\title{
Response of Long-Term Memory to Molecular Changes of BDNF in Hippocampus in Various Intensities of Physical Activity
}

\author{
Leonardo Lubis, ${ }^{1}$ Setiawan ${ }^{2}$ \\ ${ }^{1}$ Department of Anatomy and Cell Biology, Faculty of Medicine, Universitas Padjadjaran \\ ${ }^{2}$ Department of Physiology, Faculty of Medicine, Universitas Padjadjaran
}

Abstract
Objective: To analyze the physiological response of long-term memory (LTM)
hippocampus by the treatment of various intensities of physical activity.
Methods: Subjects were $7-8$ week old male Wistar rats weighed between
201-250 grams. This study was an experimental study with pre-(day-1)
and post-(day-14) design. Molecular changes reflected by the changes in the
expression of mRNA and protein of BDNF in the hippocampus. Treatment
of physical activity on the subjects was running on the Animal Treadmill
by grouping of the physical activity: light intensity at a speed of $10 \mathrm{~m} / \mathrm{min}$,
moderate intensity at a speed of 20 m/min and heavy intensity at a speed of
30 m/min. The treatment's duration was 30 minutes.Then, analysis of data
on pre (day-1) and post (day-14) which were: LTM response based on travel
time swimming test, the expression of mRNA (Ct) and protein (\%) of BDNF in
hippocampus based on RT-PCR and immunohistochemistry.

Results: The results showed that moderate intensity group caused the better physiological and molecular responses than the other groups, as follows: travel time ( 0.6260 vs 0.7270 vs 0.9400 vs. 1.4000 seconds ( $\mathrm{p}<0.05)$ ), mRNA BDNF expression (17.2320 vs 18.8800 vs 19.7540 vs $20.7750 \mathrm{Ct}(\mathrm{p}<0.05))$, and hippocampal BDNF protein expression.

Received:

January 26, 2016

Conclusions: The study conclude that the moderate intensity is the best physical activity to improve LTM as showed by the BDNF mRNA expression as well as BDNF protein in hippocampus.

Revised:

June 20, 2016

Keywords: Intensity, long-term memory, brain-derived neurotrophic factor,

Accepted: hippocampus [IJIHS. 2016;4(2):67-72]

August 3, 2016

pISSN: 2302-1381; eISSN: 2338-4506; http://dx.doi.org/10.15850/ijihs.v4n2.839

\section{Introduction}

Exercise will improve the capability of nerve system and is expected to optimize the lifetime learning and improve memory. Memory is a comprehensive sense related to the ability to store information at a certain time and may result in different responses based on the stored information. Hippocampus and Amygdala play an important role in memory formation. Hippocampus plays role in the neuronal networks to enable the delivery of

Correspondence:

Leonardo Lubis, Department of Anatomy and Cell

Biology, Faculty of Medicine, Universitas Padjadjaran-

Dr. Hasan Sadikin General Hospital

Jl. Raya Bandung-Sumedang KM 21 Jatinangor,

Indonesia

e-mail: leonardolubis@yahoo.com impulses or informations while amygdala is a structure that plays a role when it involves the emotions that arise from the experience. ${ }^{1-9}$

The memory formation requires neuronal activities as response to a information stimulus referred to as the Information Processing. Memory is formed from experience as well as from external environmental stimulation in the learning process. Stimulation from the learning process will be delivered as electrical or chemical impulses to the brain through neurons. Potentiation is electrical or chemical conduction of impulses between neurons. Long-term and repeated potentiation will result in long-term memories. ${ }^{5,9}$ Nevertheless, mechanism of the physiological response to molecular changes in the nervous system after exercise and it's effect on long-term memory 
Table 1 ANOVA Test for Differential Long-term Memory between Low, Moderate, and High Intensity Groups

\begin{tabular}{cccccccc}
\hline Variable & Group & Day & $\bar{x}(\mathbf{m i n})$ & \pm & SD & ANOVA & p Value \\
\hline \multirow{3}{*}{ Travel time } & Control & Day-1 & 1.49 & \pm & 0.06 & & \\
& \multirow{3}{*}{ Low } & Day-14 & 1.31 & \pm & 0.05 & & \\
& & Day-1 & 1.19 & \pm & 0.08 & & \\
& \multirow{2}{*}{ Moderate } & Day-14 & 0.26 & \pm & 0.25 & 3.423 & \\
& \multirow{3}{*}{ High } & Day-1 & 1.13 & \pm & 0.04 & & \\
& & Day-14 & 0.13 & \pm & 0.05 & & \\
\hline
\end{tabular}

are still not clear. Various exercise intensities play important roles in both physiological and molecular adaptations of the body. The effect of these various intensities on the long term memory formation in the hippocampus is important to be identified.

Results have shown some physical changes in the hippocampus due to regular exercises including increases in neurons, synapses and neurotransmitters which are stimulated by increased expression of both brain-derived neurotrophic factor (BDNF) mRNA and also protein. ${ }^{11-17}$ The brain-derived neurotrophic factor is a neurotrophin encoded by a gene called BDNF. In humans, the BDNF gene is found in chromosome 11 with allele variations between valine and methionine at codon 66 (Val66Met). ${ }^{10,11}$

The formation of BDNF takes place in the endoplasmic reticulum and is stored in the vesicles for later secretion into the synaptic cleft. Brain-derived neurotrophic factor serves to encourage the growth and differentiation of the new neurons (neurogenesis) and supports the ability of neurons to survive. Brain-derived neurotrophic factor active in the brain cortex, prekorteks,butdominantlyin thehippocampus. Brain-derived neurotrophic factor may affect learning and memory processes through expression of BDNF mRNA and BDNF protein synthesis in hippocampus. ${ }^{12,13}$

\section{Methods}

The subjects were 40 male Wistar rats (Rattus norvegicus) that met the following inclusion criteria: male, aged 7-8 weeks, weight 201250 grams, and in a healthy state. The study group was divided into eight groups of 5 Wistar rats: $\mathrm{K}-1$ (only treated by swimming test and thereafter will be sacrificed on day-1), K-14

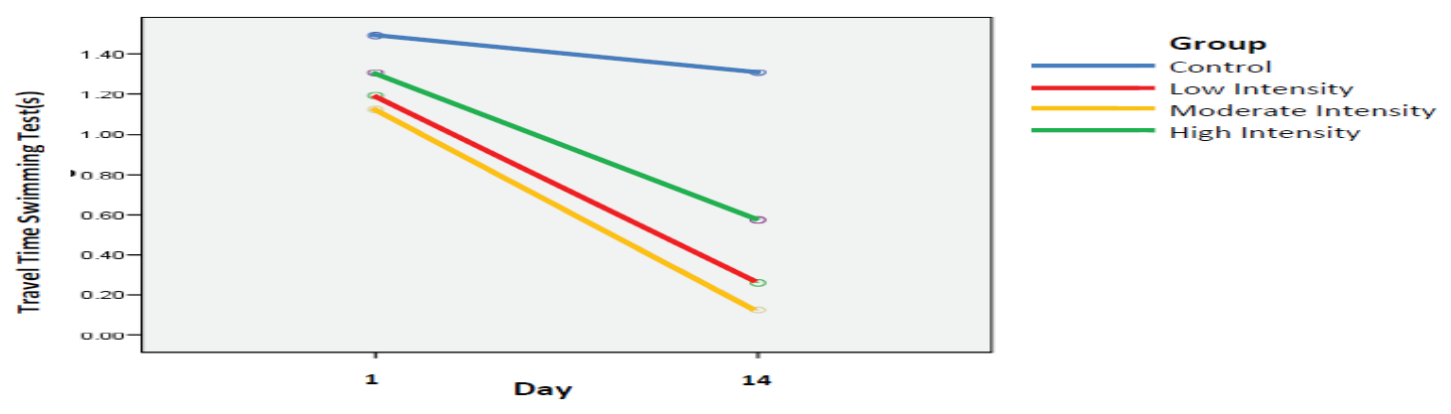

Fig. 1 Post hoc Test for Differential of Long-term Memory between Low, Moderate, and High Intensity Groups 
Table 2 Anova Test for Differential of Hippocampus mRNA BDNF Expression between Low, Moderate, and High Intensity Groups

\begin{tabular}{cccccccc}
\hline Variable & Group & Day & $\bar{x}(\mathbf{m i n})$ & \pm & SD & ANOVA & p Value \\
\hline \multirow{6}{*}{ Travel time } & Control & Day-1 & 18.01 & \pm & 1.46 & & \\
& & Day-14 & 17.75 & \pm & 1.28 & & \\
& \multirow{4}{*}{ Low } & Day-1 & 22.8 & \pm & 4.06 & & \\
& & Day-14 & 18.75 & \pm & 0.71 & 10.231 & 0.000 \\
& \multirow{4}{*}{ Hoderate } & Day-1 & 20.87 & \pm & 0.71 & & \\
& & Day-14 & 18.64 & \pm & 0.57 & & \\
& Day-1 & 18.06 & \pm & 0.78 & & \\
& & Day-14 & 16.4 & \pm & 0.55 & & \\
\hline
\end{tabular}

(only treated by swimming test on the $14^{\text {th }}$ day and thereafter will be sacrificed), R-1 \& $\mathrm{R}-14$ (treated by a low intensity at a $10 \mathrm{~m} / \mathrm{min}$ with a duration $30 \mathrm{~min}$ and finally sacrificed on day-1 for R-1 and sacrificed on day-14 for R-14), S-1 and S-14 (moderate intensity group, $20 \mathrm{~m} / \mathrm{min}$ with a duration $30 \mathrm{~min}$ treadmill exercise), B-1 and B-14 (high intensity group, $30 \mathrm{~m} / \mathrm{min}$ with a duration $30 \mathrm{~min}$ treadmill exercise). The S-1, S-4, B-1, and B-14 were sacrificed at a similar time and procedure.

The health of the animal was determined based on the following signs: hair does not fall out and brightly colored; nails intact with no damage; tail looks clean with no wound or injury seen; normal aggressiveness; and has good appetite. Hippocampal BDNF mRNA is a messenger RNA of brain-derived neurotrophic factor expressed in the hippocampus tissues of wistar rats. The BDNF mRNA expression was measured using RT-PCR method ( $\mathrm{Ct}$ (cycling-threshold)). Cycling-threshold in the reaction cycle threshold of the RT-PCR method is seen as hippocampal BDNF mRNA expression that ranges from the amplification to the replication processes. The hippocampal BDNF protein is a protein which is encoded by hippocampal BDNF gene. Brain-derived neurotrophic factor expression in wistar rat's hippocampal tissue can be observed through immunohistochemical staining that is focused on cornu ammonis 1 (CA1) area. The criteria for the assessment of hippocampal BDNF protein expression is based on the intensity of brown staining (immunohistochemistry) in the CA1 area of the hippocampus. In this study, the number of immunohistochemical preparations observed for the hippocampal BDNF expression in each group was five and the observations of the hippocampal BDNF expression was based on a percentage of the preparations number in each group within percent unit (\%). The focus of the hippocampal BDNF expression analysis in this study was the expression of BDNF in hippocampal strong positive criteria ( + + strong).

Long-term memory (LTM) is time needed (in seconds) by the rats to swim to the platform (target) in the swimming test. The increase in LTM is visible from the shorter time required

Table 3 Crosstabs for Differential of Protein BDNF Expression in Cell Body between Low, Moderate and High Intensity Groups on Day-1 and Day-14

\begin{tabular}{|c|c|c|c|c|c|c|}
\hline Day & & & Control & Low & Moderate & High \\
\hline \multirow[t]{2}{*}{ Day-1 } & & Number & 1 & 2 & 2 & 3 \\
\hline & Cell body & $(+)$ strong $(\%)$ & $20 \%$ & $40 \%$ & $40 \%$ & $60 \%$ \\
\hline \multirow[t]{2}{*}{ Day -14} & & Number & 1 & 4 & 5 & 1 \\
\hline & & $(+)$ strong $(\%)$ & $20 \%$ & $80 \%$ & $100 \%$ & $20 \%$ \\
\hline
\end{tabular}


to finish the task. The swimming test is a test performed by the Wistar rats where they were put in the swimming container and the time they take to reach the target platform or pedestal (in seconds) placed in the container is measured. The swimming container had a diameter of 1.5 meter and a depth of 0.5 meter. The bottom of the container was divided into four sections or quadrants and a platform or pedestal was placed on the quadrant.

The analysis of hippocampal BDNF mRNA was conducted by quantitative real time PCR (RT-PCR). Sampling was done after sacrificing the subject by decapitation at the head and the brain was removed. The hippocampal tissue was then collected for RNA isolation.

Oligonucleotide primer. The primer of specific genes was taken from the Primer Data Bank. The primer and probe used in this study were: RNA Primer Rat BDNF

\section{AGCAGCCCTGGTATCAGCTATCAAACAAGGAGGT- GATAGAATGCATCACCCAGGGCAGAGTCGTTCAGG- GGCGTCGCACGTGTCGCGAGGAGGTGTAC- GAGGTGATGGTGGGATGGTGGGAGGGGGAAC- CACTCCTTCAGAACTTGGCGA}

Forward 5'AGCAGCCCTGGTATCAGCTA 3' ->Ekson 18

Reverse 5'TCGCCAAGTTCTGAAGGAGT 3' -> Ekson 19

Reverse transcription. Superscript FirstStrand Synthesis System for RT-PCR was used for reverse transcription. The procedure used was based on the Invitrogen protocol.

Hippocampus BDNF protein examination was conducted using the immunohistochemical staining method. The principle of this staining is that the anti-BDNF antibody genes will bind to the antibodies. The rat anti-BDNF antibody reagents used were the BDNF N20 Santa Cruz, USA. The immunohistochemical examination procedure consists of four stages, namely: paraffin block preparation, sectioning, HE staining, and immunohistochemistry.

The entire procedure was performed based on the procedure approved by the Health Research Ethic Commitee of the Faculty of Medicine, Universitas Padjadjaran. The wistar rats were treated according to the feasibility and as sentient beings in accordance with the Helsinki agreement (The Declaration of Helsinki) 2004 issued by the World Medical Association. Rats were placed individually in standard cages and were given food and drink ad libitum.

During the study, the rats were kept at room temperature of $24 \pm 10 \mathrm{C}$ with 12 hours light -12 hours dark. Rats were placed in $60 \times 40 \times 30 \mathrm{~cm}$ cages with each cage contained 5 rats. The cages were arranged on several shelves.

During the study, the rats performed a physical activity in the form of running on a treadmill as prescribed in the study procedure. Two mL of blood was drawn from the rat's heart under anesthesia on day-1 and -14. After treatment was completed on day 1 and 14, rats were sacrificed by decapitation that they died almost instantly Actions were carried out separately from the existence of other animals. Rats that had been sacrificed for the good of humanity should be respected and treated humanely; hence, they were buried.

\section{Results}

The ANOVA $(p<0,05)$ and the Post-hoc results show the physiological response of LTM based on the time achieved in swimming test (Table 1). They were 0.6260 vs 0.7270 vs 0.9410 vs 1.4000 seconds (Fig. 1). From the ANOVA $(p<0.05)$ analysis, it was apparent that there were molecular changes in the mRNA BDNF expression, based on the cycling treshold in the RT-PCR method (Table 2 and Fig. 2).

The post-hoc results of the mRNA BDNF expression on moderate, low, high and controls

Table 4 Crosstabs for Differential Protein BDNF Expression in Axons of Low, Moderate, and High Intensity Groups on Day-1 and Day-14

\begin{tabular}{|c|c|c|c|c|c|c|}
\hline Day & & & Control & Low & Moderate & High \\
\hline \multirow[t]{2}{*}{ Day-1 } & & Number & 1 & 1 & 2 & 3 \\
\hline & Axon & $(+)$ strong $(\%)$ & $20 \%$ & $20 \%$ & $40 \%$ & $60 \%$ \\
\hline \multirow[t]{2}{*}{ Day -14} & & Number & 2 & 2 & 5 & 1 \\
\hline & & $(+)$ strong $(\%)$ & $40 \%$ & $40 \%$ & $100 \%$ & $20 \%$ \\
\hline
\end{tabular}




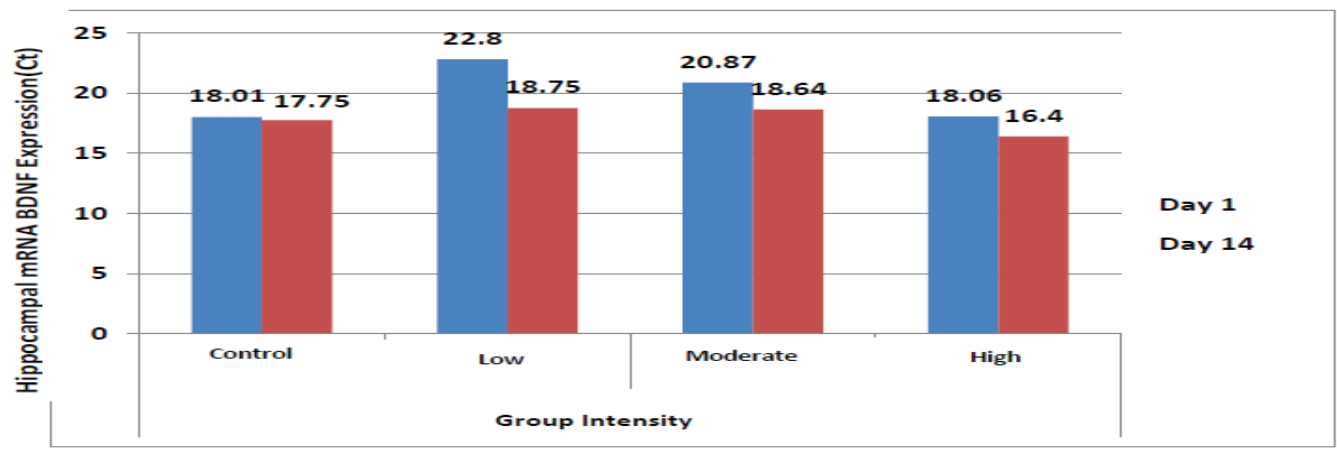

Fig. 2 Differential of Hippocampus mRNA BDNF Expression between Low, Moderate, and High Intensity Groups

were 17.2320 vs 18.8800 vs 19.7540 vs 20.7750, respectively. The immunochemistry analysis showed the expression of the hippocampus protein BDNF expression which are described (Table 3 and 4 ).

\section{Discussion}

The results of the present study showed that the moderate physical activities can improve LTM which was apparent from the shorter travel time in swimming test when compared to other physical activity intensities. These regular and well programmed activities with moderate intensity have been proven to be effective for optimized cardiovascular and respiratory functions as well as perfusion in all areas including the brain system. The well supported perfusion system in brain tissue, in terms of nutrition, oxygen and glycogen, will improve the brain function, specifically the hippocampus that plays an important role in LTM formation especially in responding to the external environment. ${ }^{1-3,6-8}$

Long-term memory is a continual process of repetition and association of short-term memory, which is a temporary potentiation of neuronal connection. ${ }^{4,5,9}$ The long-term memory need consolidated gene expression and protein synthesis with the consolidation occurs in the hippocampus, the most potential area in the brain system. This consolidation is mediated by a specific molecule, BDNF. 13,15,18,19

Brain-derived neurotrophic factor protein expression in the cell body and axon of the hippocampus reflects that BDNF synthesized in cell body is then distributed through the axons of hippocampus neurons. This physiological process gives us an insight into the molecular mechanism in hippocampus neuron improvement in LTM formation. ${ }^{14,15,16}$ The moderate physical activity could stimulate the neurogenesis in hippocampus that would then lead to the complexity of dendrites and then finally influence the learning and memory process. ${ }^{17,18}$

Brain-derived neurotrophic factor, an active molecule at cornuamnosis 1 (CA1) area on hippocampus, is the most active neurotrophin in stimulating and controlling the neurogenesis process. Physical activities can be considered as on of the precipitating factors to initiate this process. ${ }^{19,20}$

It is concluded that the physical activities with moderate intensity is the best activity to improvE BDNF mRNA and protein expressions in hippocampus, which could optimize the long-term memory formation.

\section{References}

1. Cookson MR, Hardy J. The persistence of memory. New Engl J Med. 2006;21(355):26978.
2. Alaei H, Moloudi R, Sarkaki AR, AziziMalekabadi H, Hanninen O. Daily running promotes spatial learning and memory in rats. 
Pathophysiology. 2007;14(2):105-8.

3. Kraemer WJ, Fleck SJ, Deschenes MR. Exercise physiology: integrating theory and application. Philadelphia; Wolters Kluwer Lipponcott Williams and Wilkins; 2012.

4. Andel R, Crowe M, Pedersen NL, Fratiglioni L, Johansson B, Gatz M. physical exercise at midlife and risk of dementia three decades later: a population-based study of Swedish twins. J Gerontol Biol Sci. 2008;63(1):62-6.

5. Bekinschtein $\mathrm{P}$, Cammarota $\mathrm{M}$, Igaz LM, Bevilaqua LR, Izquierdo I, Medina JH. Persistence of long-term memory storage requires a late protein synthesis- and BDNFdependent phase in the hippocampus. Neuron. 2007;53(2):261-77.

6. Greenberg ME1, Xu B, Lu B, Hempstead BL. New insights in the biology of BDNF synthesis and release: implications in CNS Function. J Neurosci. 2009;29(41):12764-7.

7. Columbus Instruments. Treadmill Software, Treadmill Controller and the Exer 3/6 Treadmill Instruction Manual. [cited 2015 May 6]. Available from: http://animalactivity.com/ Mouse-Rat-Treadmill.

8. Huang AM, Jen CJ, Chen HF, Yu L, Kuo YM, Chen HI. Compulsive exercise acutely upregulates rat hippocampal brain-derived neurotrophic factor. J Neural Transm (Vienna). 2006;113(7):803-11.

9. Rex CS, Lin CY, Kramár EA, Chen LY, Gall CM, Lynch G. Brain-derived neurotrophic factor promotes long-term potentiation related cytoskeletal changes in adult hippocampus. J Neurosci. 2007;27(11):3017-29.

10. Hong EJ, McCord AE, Greenberg ME. A biological function for the neuronal activity-dependent component of BDNF transcription in the development of cortical inhibition. Neuron. 2008;60(4):610-24.

11. Yang J, Siao CJ, Nagappan G, Marinic T, Jing D,
McGrath K, et al. Neuronal release of proBDNF. Nat Neurosci. 2009;12(2):113-5.

12. Sibley BA, Beilock SL. Exercise and working memory:anindividualdifferencesinvestigation. J Sport Exerc Psychol. 2007;29(6)783-91.

13. Aid T, Kazantseva A, Piirsoo M, Palm K, Timmusk T. Mouse and rat BDNF gene structure and expression revisted. J Neurosci Res. 2007;85(3):525-35.

14. Castellano V, Patel DI, Yarrow JF., McCoy SC, Blazina A, White LJ. Acute and chronic exercise influence serum brain-derived neurotrophic factor in multiple sclerosis. FASEB J. 2007;21(1):954-7.

15. Cao X, Cui Z, Feng R, Tang YP, Qin Z, Mei B, et al. Maintenance of superior learning and memory function in NR2B transgenic mice during ageing. Eur J Neurosci. 2007;25(6):1815-22.

16. Wu J, Rowan MJ, Anwyl R. Long-term potentiation is mediated by multiple kinase cascades involving CaMKII or either PKA or p42/44 MAPK in the adult rat dentate gyrus in vitro. J Neurophysiol. 2006. 95(6):3519-27.

17. Li F, Tsien JZ. Memory and the NMDA receptors. N Engl J Med. 2009;361(3):302-3.

18. Kakegawa W, Miyazaki T, Hirai H, Motohashi J, Mishina M, Watanabe M, etal. Ca2+ permeability of the channel pore is not essential for the $\delta 2$ glutamate receptor to regulate synaptic plasticity and motor coordination. J Physiol. 2007;579(Pt 3):729-35.

19. Cohen-Matsliah SI, Brosh I, Rosenblum K, Barkai E. A novel role for extracellular signalregulated kinase in maintaining long-term memory-relevant excitability. J Neurosci. 2007;27(46):12584-9.

20. Barker GRI, Warburton EC. NMDA receptor plasticity in the perirhinal and prefrontal cortices is crucial for the acquisition of longterm object-in-place associative memory. J Neurosci. 2008;28(11):2837-44. 